\title{
Release of carbon granules from cigarettes with charcoal filters
}

\author{
John L Pauly, Sharon J Stegmeier, Andrew G Mayer, Joel D Lesses, Richard J Streck
}

\begin{abstract}
Objective-To inspect cigarettes with a triple granular filter for charcoal granules on the cut filter surface and, if present, to determine whether the charcoal granules on the filter are released during smoking. Design-400 Lark cigarettes in 20 packs were examined individually by each of three investigators for the presence of charcoal granules on the cut surface of the cellulose acetate filter. Without removing the cigarettes from the pack, the filters were examined with a stereo zoom microscope for charcoal granules. The percentage of cigarettes that had charcoal granules was defined, and charcoal gxanules on each filter were counted. Randomly selected cigarettes were then smoked by consenting adult smokers to assess whether the charcoal granules were released during smoking. Lark cigarettes were smoked with a conventional cigarette holder that had been configured to contain an in-line membrane. After smoking, the membrane was analysed microscopically for charcoal granules and other components of the filter that had been released during smoking.
\end{abstract}

Results-Charcoal granules were observed in $79.8 \%(319 / 400)$ of the cigarettes examined. The number of granules per cigarette was 3.3 (SD 3.7). Gaps between the tipping papers-the wrapping papers that surround the filter-were often seen $(70 \% ; 242 \quad(71) ; \mathbf{n}=400$ cigarettes $)$. Further, the charcoal cavity was about $60 \%$ empty. For all smokers $(n=8 / 8)$, charcoal granules were released during smoking. The number of charcoal granules captured on the membranes was 22.5 (16.2) per cigarette.

Conchusions-Charcoal granules are incorporated into cigarette filters to aid in removing toxins in cigarette smoke. In studies of Lark, a popular American cigarette with a charcoal filter, charcoal gran m ales were observed on the filter surface, and were released from the filter when the cigarettes were smoked. During smoking, the toxin-containing charcoal granules are inhaled or ingested. The specific adverse health effects of inhaling or ingesting carbon granules have not been addressed; nevertheless, the smoker, as an educated consumer, should be informed of the possible health risks.
Keywords: cigarette filter; charcoal; fibres; gas

Most (more than 95\%) of cigarettes marketed today in the United States have filters. ${ }^{13}$ We believe that the smoker perceives the filter of a cigarette to be both safe and efficient. However, recent observations in our laboratory challenged this view. For example, we have observed the release of cellulose acetate fibres from cigarette filters." "These filter fibres were: (a) observed trapped between the cellophane wrapper and the unopened pack of cigarettes; (b) present in the residue at the bottom of packs; (c) discharged from the filter when cigam rettes were tapped from a height of $3.5 \mathrm{~cm}$ or dropped from $15 \mathrm{~cm}$; (d) liberated when the filter was touched to the mouth of a human volunteer or the surface of a piece of bovine liver; and (e) released when cigarettes were smoked mechanically.

We believe that cellulose acetate cigarette filter fibres pose an additional health hazard to the smoker because the fibres are released during smoking. The tar coated synthetic fibres, resistant to biodegradation in the human body, are inhaled or ingested and may therefore pose an additional health risk to the smoker."

In the course of our ongoing studies, the filters of cigarettes with charcoal filters were examined microscopically, (In this paper we have adopted the convention of using the terms charcoal, activated charcoal, carbon, and coal in describing these types of cigarette filters, see ref. 12.) We report here that charcoal granules are present on the cut filter surface, and within gaps between the cigarette wrapping papers (that is, between the plug wrap surrounding the cellulose acetate filter tow and the papers encasing the charcoal granules). We predicted that during normal smoking behaviour these charcoal granules would be discharged from charcoal filters in such a way that they would be inhaled or ingested.

Many investigators have reported that cigarette smoking is a complex behaviour with numerous variables that are difficult to replicate mechanically. ${ }^{5-3}$ To enable us to extrapolate the fandings more accurately to the smoking population as a whole, our study was conducted with consenting adults, who were asked to smoke charcoal filter cigarettes using a cigarette holder that we had modified so as to contain an in-line entrapment screen. The screen was selected and configured with the intent of capturing filter elements released during smoking.

Moreover, because human smokers are individualistic in the manner in which they smoke, we concluded that it would be more instructive 
if we did not control the individuals' normal smoking behaviour. We know of no other published studies that have used human subjects to test cigarette filter integrity or defects.

\section{Methods \\ SUBJECTS \\ All protocols and procedures used in the human smoking study were approved by the clinical investigations committee of the Roswell Park Cancer Institute. Subjects were adult $(>25$ years of age) long term smokers who were smoling currently at least 20 cigarettes per day. The volunteers were informed verbally of the purpose and scope of this study. Thereafter, a signed and witnessed consent was obtained. All participants were compensated financially.}

CIGARETTES USED

Cigarettes analysed were Lark cigarettes. Lark cigarettes are manufactured by Liggett Group. Lark cigarettes have a triple granular filter composed of cellulose acetate fibres and activated charcoal and have been described in detail elsewhere. ${ }^{3-8}$ A recently published book provided a historical overview of the origin of charcoal filters and the development of the filter on the Lark cigarettes. "An exploded view of a triple granular filter is illustrated in fig 1 .

ANALXSIS OF FILTERS FOR CHARCOAL GRANULES Many of the tests reported here were performed with 20 packs of Lark cigarettes which had been purchased locally (two packs from each of 10 vendors). Each pack of Lark cigarettes received a code number, and was then opened carefully in the laboratory. The top wrapper of each pack was cut off with scissors. Without removing the cigarettes from the pack, the filter surfaces of the non-smoked cigarettes were examined with a stereo zoom microscope (Stereomaster; Fisher Scientific).

In our initial examinations, the filters of randomly selected cigarettes, with and without charcoal filters, were inspected for the presence of charcoal granules and the integrity of the wrapping papers. For quantitative analysis, the stereo zoom microscope was adjusted to permit viewing of the whole cut surface of the cigarette filter (15-fold magnification; $\times 1.5$ objective and $\times 10$ ocular). At $\times 8$ magnification, the resolution was about $13.7 \mu \mathrm{m}$; at $\times 40$, the resolution was about $7.4 \mu \mathrm{m}$ (personal communication, Carton Optical Industries, Tokyo, Japan).

Charcoal granules observed on the filter surface were counted by each of three investigators. The three readers examined the entire filter and then counted the number of well defined conspicuous carbon particles in each of the four filter quadrants. The number of particles was then scored as: 0 (nil), 1-5 (low), 6-10 (medium), >10 particles (high).

Thereafter, the tipping papers-the wrapping papers that surround the filter (fig 1) rryara anoluced to idantify mortiome of tha gap, no charcoal (low); >1 gap, no charcoal (medium); and $>1$ gap, with charcoal in the gap (high).

For all tests, a formal measure of the degree of association (for example, agreement) of the counts recorded by three independent observers was computed using the $\kappa$ test. ${ }^{10}$

For comparison, other cigarettes of various popular American brands were included as controls. These control cigarettes had filters that did not contain charcoal.

\section{MODIFIED CIGARETTE HOLDER}

With the safeguards against contamination (see below), a cigarette holder was used to measure the release of charcoal granules from charcoal filter cigarettes during human smoking. The efficiency of the holder and entrapment device was qualified initially in repeated trials in which Lark and other brands of cigarettes fixed to the holder were smoked mechanically.

A conventional cigarette holder (Denicotea; Denicotea Co (Germany), distributed by Lane), purchased from a local retail shop, was first removed from its cardboard packaging. The cartridge of Denicotea crystals was removed and discarded. The cigarette holder was then soaked in $20 \%$ bleach for 30 minutes and rinsed with deionised water. This was followed by a second wash with Palmolive detergent (Colgate-Palmolive Company, New York City) and repeated rinsing in deionised water.

After the cigarette holder had been dried in an oven at $56^{\circ} \mathrm{C}$, an entrapment device was added. This device consisted of an $85 \times 250 \mathrm{~mm}$ polyurethane sponge cylinder (product $\mathrm{Nc}$ 1030; 1.016 density; 30 ILD; Foamax, Arcade New York). Positioned on the upstream end 0 the cylinder was a white, fine mesh, polyeste screen (FN 5720-010; cut off $\sim 0.1 \mu \mathrm{m}$; Polyl ite).

The entrapment device was positioned in th proximal segment of the two piece holder When a cigarette was positioned in the holdel the end of the cigarette filter was approximatel 3 to $5 \mathrm{~mm}$ from the entrapment screen. Th cigarette filter was not permitted to contact th screen. The assembled smoking apparatus wa transported in a capped Falcon polystyrer tube $(17 \times 100 \mathrm{~mm}$; No 2051 ; Bector Dickinson, Franklin Lakes, New Jersey).

SAFEGUARD AGAINST AIRBORNE CONTAMINANTS To prevent the contamination of screens an other materials used in the study by airbor fibres and debris, the following precautio were implemented. All glass slides, cor glasses, instruments, and other items used the study were precleaned and-immediate before using-flamed with $100 \%$ ethan Inspection of the slides and cover glass before use showed that they contained no $c$ bon particles or fibres. Other than act smoking, all procedures were performed unc tha mantantinn of a laminar forr hond with d 

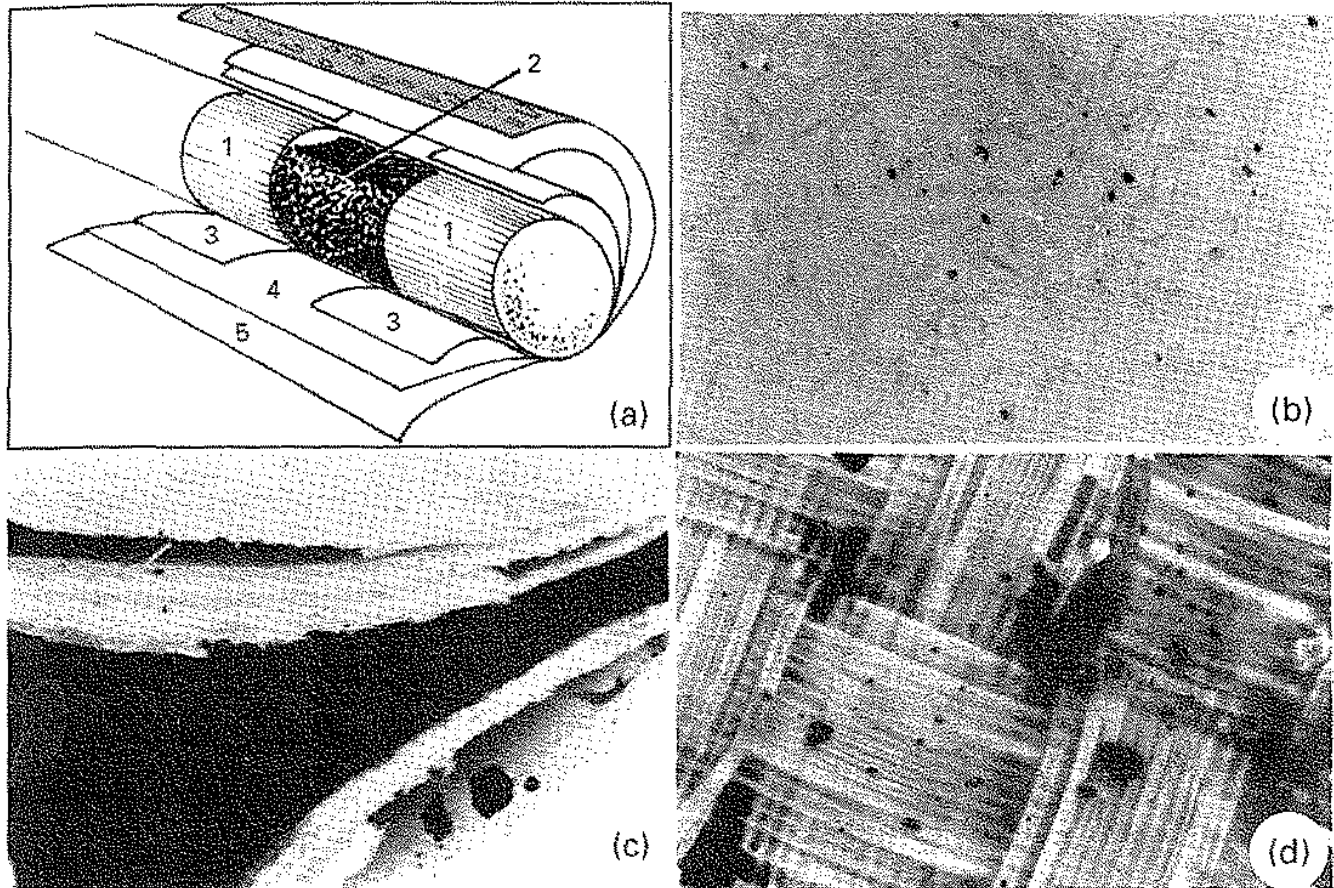

Figure 1 Release of charcoal granules from Lark cigarettes. (a) A schematic chrazoing of a trible granular fiter ( $1=$ collulose acetate filter plug; $2=$ charcoal granules in middle chamber; $3=$ cellulose acetate plug wrap; $4=$ triple filter wrap;

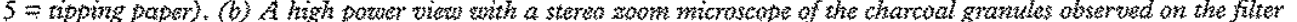
surface of a non-smoked Lark cigarette ( $\times 23$; original magnification $\times 40)$; (c) a similar view showing the gaps between the wropping papers of two Law cigarettes that had not been removed from the cigarette pach. Note the prominevt charcoal granules located within the crevice of the lower cigareite. This illustration is representation of the worapping paper separations identified in $70.4 \%(282 / 400)$ of the cigarettes examined (stereo $200 m$ microscope, $\times 23$; original magnification $\times 40)$. (d) $A$

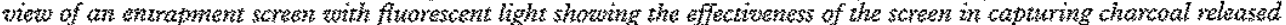
from a Lark cigarette that had been smoked by an adult volunteer. Also note the variability in stze of the charcoul granutes that foll from the filtor (original atagnification $\times 100$ reduced to $59 \%$ for publication).

SMOKING ROUTINE

After the investigator had carefully placed a Lark cigarette into the holder, the participants lit the cigarette in their usual manner. The smokers were instructed to smoke the cigarette with their usual smoking routine (for example, puff volume and draw duration). The volunteer, however, was instructed not to inhale. After smoking, the cigarette was removed with forceps and placed in a capped tube. Likewise, the holder was placed in a prelabelled Falcon tube, and both tubes were taken to the laboratory. Each subject smoked one cigarette.

\section{ANALYSIS OF ENTRAPMENT SCREEN}

Under the protection of a laminar flow hood, the entrapment screen was removed from the polyurethane sponge cylinder with forceps. For this purpose, the screen was placed on a $3 \times 1$ inch $(7.5 \times 2.5 \mathrm{~cm}) \times 1.0 \mathrm{~mm}$ glass slide. A few dabs $(-50 \mu \mathrm{m})$ of high vacuum grease (Dow Corning, Midland, Michigan) were applied to the glass slide. A microscope cover glass ( $24 \times$ $60 \mathrm{~mm}$, No 1 thickness) was then positioned over the screen, and secured in position by applying gentle pressure to the grease.

The screen was then examined microscopically for the presence of charcoal granules, as well as other cigarette filter components released during smoking. 'The microscope used was configured to permit viewing with white, polarising, and fluorescent light (Reichert-Jung Microstar IV/Photostar, Buffalo, New York)."

Charcoal particles on the cigarette filter surface and on the entrapment screen were meas- ured using an ocular micrometer, In a few instances, more precise measurements were also made with the use of a confocal laser scanning microscope."

\section{ANALUSTS OF COLLECTION MEMBRANE}

Working under the protection of a laminar flow hood, each extrapment device was removed from the cigarette holder. Each holder was then flushed with $100 \%$ ethanol to recover any charcoal granules and other filter components which might have adhered to the interior walls of the apparatus. The alcohol wash was collected and filtered through a micropore membrane (diameter, $25 \mathrm{~mm}$; Millipore, Bedford, Massachusetts) using a glass vacuum filter assembly (Cat No 419325; Wheaton, Millville, New Jersey).

The micropore collection membrane was then removed from the filtration device with forceps and allowed to dry thoroughly in a clean covered glass dish. After drying, the membrane was affixed onto a $75 \times 50 \mathrm{~mm}$ glass slide with S/P Accu-Mount 60 mounting medium (Cat No M7630-1; Baxter Scientific Products, Riverdale, New Jersey). A $45 \times$ $50 \mathrm{~mm}$ cover glass was positioned over the membrane and secured with pressure from blunt nosed forceps. These collection membranes were examined microscopically as described above.

ANALYSYS OF THE POLYURETHANE SPONGE CYLINDER

The polyurethane sponge cylinder was inspected with a stereo zoom microscope for 


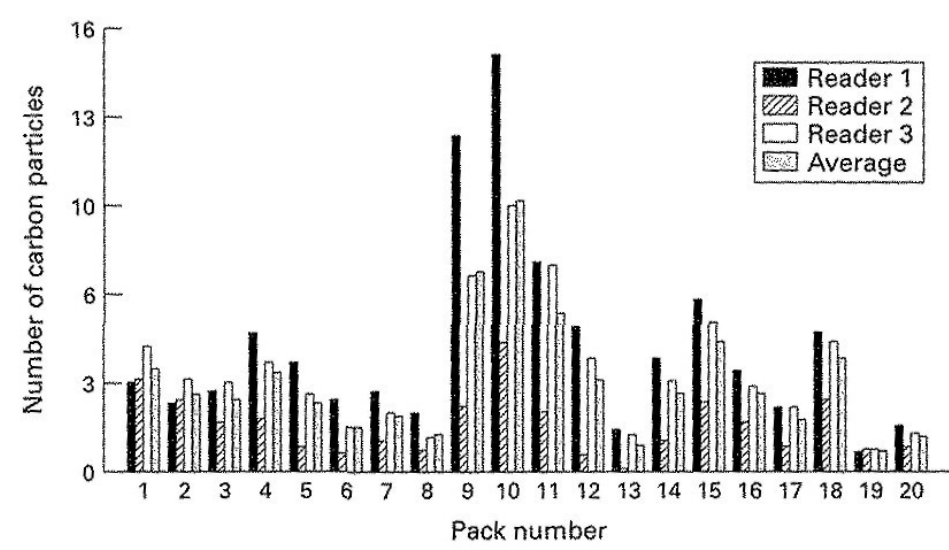

Figure 2 Enumeration by three independent investigators of the charcoal granules visible on the filter surface of the non-smoked cigarettes contained within 20 packs of Lark cigarettes. Each bar represents the mean number of charcoal granules per cigarette in a given pack seen by the indicated observer. The mean values for the investigators, individually and totally, are presented.

the presence of adherent cigarette filter components.

PHOTOGRAPHIC DOCUMENTATION

Photographse of the filter surface of the non-smoked Lark cigarettes, entrapment screens, and collection membranes were obtained with Kodak Ektachrome Elite $35 \mathrm{~mm}$ film (ISO 400). Original magnification of the image in the Ektachrome film is given in the figure legend.

\section{Results}

ANALYSIS OF CIGARETTE FILTERS FOR CHARCOAL PARTICLES

Our initial microscopic observations showed that charcoal granules were present on the filters of most Lark cigarettes. The granules varied in size, ranging from large particles (> $1.0 \mathrm{~mm}$ ) to dust-like "fines" that were at the threshold of resolution with a stereo zoom microscope (approximately $7.4 \mu \mathrm{m}$; fig $1 \mathrm{~b}, \mathrm{c}$, d).

The carbon granules were distributed randomly on any given filter. Some granules were on the filter surface whereas others were enmeshed relatively deeply (approximately 1 to $2 \mathrm{~mm}$ ) within the filter rod, which consisted of thousands of cellulose acetate fibres (diameter approximately 20 to $50 \mu \mathrm{m}$; fig $1 \mathrm{~b}$ ).

The distribution on top and within the cigarette filter, as well as the variability in the size of the carbon granules, often complicated efforts at enumeration (fig $1 \mathrm{~b}$ and c). Nevertheless, three investigators examined Lark cigarettes in 20 packs ( $n=400$ cigarettes) for carbon particles. The percentages of filters of the non-smoked cigarettes-retained within the pack-with charcoal granules were as follows: observer A, 87\% (349/400 cigarettes); B, 65\% $(262 / 400) ; C, 86 \%(345 / 400)$. The mean of A, $\mathrm{B}$, and $\mathrm{C}$ was $80 \%(318 / 400)$. The coefficient of correlation among the three readers was as follows: $\mathrm{A} v \mathrm{~B}, 0.35 ; \mathrm{A} v \mathrm{C}, 0.58$; and $\mathrm{B} v \mathrm{C}$, 0.37 .

Using the same microscopic examination procedure, charcoal granules were not observed on the filters of cigarettes without charcoal filters $(n=0 / 400$ cigarettes; readers $A, B$, and $C$ ).

The average number of carbon particles on the Lark cigarette filters is shown in fig 2 . The values illustrated in this figure are those of the same three observers, defined individually and collectively. The mean number of carbon particles on each filter was 3.3 (SD 3.7). The $k$ test results for the observations of the number of charcoal particles were: $\mathrm{A} v \mathrm{~B}, 0.42 ; \mathrm{A} v \mathrm{C}$, 0.25 ; and $\mathrm{B} v \mathrm{C}, 0.28$.

Considerable variability was noted for the number of charcoal particles present on the filters of cigarettes from different packs. As illustrated, in pack No 19 , very few particles were present on the filters $(0.8(0.02)$ charcoal granules per cigarette; range 0 to 6 ). In contrast, for other packs (for example, pack No 10), numerous charcoal granules were present $(9.7$ (4.3) charcoal granules per cigarette; range 0 to 20 ).

Figure 1 presents a schematic picture of a Lark cigarette with a triple granular filter (fig 1a) as well as views of charcoal granules on the filter surface (fig 1b), within a gap formed by wrapping papers and the bundle of cellulose acetate fibres (fig 1c), and released during human smoking (fig 1d).

Figure 1 also illustrates the variability in the size of the carbon on the cut surface of the cigarette filter (fig $1 \mathrm{~b}$ and d) and released during smoking from the charcoal filter (fig $1 \mathrm{~d}$ ).

\section{FILTER GAP WITH CHARCOAL GRANULES}

Particularly noteworthy was the fact that charcoal granules were also observed in a gap formed by the bundle of cellulose acetate fibres and the wrapping papers (fig 1c). Gaps were located between the cellulose acetate plug wrap and the triple filter wrap (fig 1a, plug wrap " 3 " and triple filter wrap " 4 "; gap illustrated in fig 1c). Gaps were also observed between the cellulose acetate filter plug and the plug wrap (fig 1 a, filter plug " 1 " and plug wrap " 3 "; gap not illustrated). The gaps on the Lark cigarette filter was observed frequently $(70 \% ; 282 / 400$ cigarettes (SD 71); three readers). The $K$ test values were as follows: $\mathrm{A} v \mathrm{~B}, 0.42 ; \mathrm{A} v \mathrm{C}, 0.25$ and $\mathrm{B} v \mathrm{C}, 0.28$.

The dimensions of the gap (that is, width length, and depth) varied markedly. In some instances, the gap could be traced deep into the filter where it terminated at the charcos loaded middle chamber. This determinatiot was made by cutting the filter tipping papt longitudinally and following a continuous pat of charcoal fines streaming from the middit chamber to the filter surface.

Of 400 Lark cigarettes examined, $70.4 \%$ displayed three or more charcoal granule within the gap. As illustrated in fig $1 c$, the granules observed within the cavity were oft very large; in several instances, the observe carbon particles were $100 \mu \mathrm{m}$ or more in diam eter.

CHARCOAL IN THE MIDDLE FILTER CHAMBER The amount of charcoal in the mid compartment (that is, the filter cavity) of cigarettes varied considerably (range 25.5 $78.8 \mathrm{mg} /$ cavity; mean (SD), 56.6 (13 $^{3}$ 
mg/cavity; $\mathrm{n}=20$ cigarettes). The charcoal capacity was established by measuring the weight of charcoal required to fill the flter cavm ity. The amount of charcoal excised from the filter of tandomily selected Lark cigaretres required to fill the chamber ranged from 115.0 to $169.4 \mathrm{mg}$ (142.5 (11.7) $\mathrm{mg}$ ). Thus the chamber of Lark cigarettes was approximately $60.0 \%$ empty (observed capacity, 56.6/142.5 $\mathrm{mg}$ charcoal/cavity).

CHARCOAE RELEASED FROM THE CIGARETTE WILTER DUREVG SMOKMNG

The cigarette holder with the in-line entrapment screen proved to be a simple, efficient, and inexpensive device for collecting charcoal and other cigarette filter elements released during smoking.

The resistance to draw (RTD; that is, pressure drop) defines the amount of suction that must be used by the smoker to pull smoke through the filter. For the in-line entrapment device alone, the RTD was $10 \mathrm{~mm} \mathrm{H}_{2} \mathrm{O}$. For cigarettes without the entrapment device, the $\mathrm{RTD}$ was 65 to $72 \mathrm{~mm} \mathrm{H}_{2} \mathrm{O}$ (see also Raker et $\left.a l^{72}\right)$.

When this device was used for snoking cigam rettes that had filters without charcoal, no carbon particles were obseryed on the entrapment screen. In contrast, carbon was discharged from the charcoal filters of all Lark cigarettes during smoking by adult volunteers. The average number of charcoal particles released from the filter of a cigarette and captured onto the in-line screen was 22.5 (16.2) particles cigarette (eight smokers; one cigarette per smoker).

Cellulose acetate cigarette filter fibres were also observed on the entrapment screen. The morphology and structures of these fibres were such that they could readily be distinguished from paper and tobacco fibres that were also present on the entrapment screen (not illustrated).

In addition, all of the Lark cigarettes tested released charcoal granules that were recovered in the wash of the modified cigarette holder. The quantity and small size of the charcoal granules which escaped the entrapment screen hindered efforts to enumerate them. However, of the eight polyurethane sponge cylinders examined, one contained a single charcoal granule. Thus the number of charcoal particles observed on the in-line screen of the entrapment device represented an unknown fraction of the total charcoal particles discharged from the filter.

\section{Discussion}

The rapid increase in the market share of filter cigarettes in the 1950 s and 1960 s mirrored the increased awareness of the health risks associated with cigarette smoking. ${ }^{13}$ Observations reported during the early 1960 s showed that cigarette smoke harms ciliated epithelial cells that line the respiratory tract and which aid in clearing inhaled particulates. ${ }^{1-3}$ \$

It is noteworthy that the majority of the toxins are not present in the particulate phase (that is, tobacco tar) but, rather, are in the gas or vapour phase of the cigarette smoke. Moreover, the smooth and non-porous nature of cellulose acetate fibres used in the filter does not provide a sufficient surface area to efiectively adsorb gaseous material. ${ }^{3}$ In addition to the inadequate surace area for the adsorption of gaseous material, the cellulose acetate filter fibres have no significant selectivity. "The notable exception is phenol, which is soluble in cellulose acetate filter material. Cellulose acetate, however, permits passage of hydrogen cyanide and hydrogen sulphide.

Activated charcoal has been used for more than 25 years to produce cigarettes with charcoal filters. Today, the most prominent types of filters are cavity and dual coal filters."

In cavity filters, charcoal is positioned in a void between two segments of cellulose acetate filter plugs." Among the most widely used charcoal filters is a type of cavity filter that has been designated as a triple granular filter, of which Lark is but one example" (fig 1a; also see Raker et $a l^{2}$, dual filter $v$ triple granular). In dual coal filters, the charcoal is distributed randomily and enmeshed within the tobacco tow.

During the last year, a third type of charcoal filter has been introduced, in which carbon has been incorporated into a paper sheet. In these filters, this carbon paper has been grooved (that is, crimped) to achieve a higher surface area of contact between the carbon and cigarette smoke. ${ }^{12}$

Charcoal acts as an adsorbent because of its high specific surface area $\left(1000 \mathrm{~m} 1200 \mathrm{~m}^{2} / \mathrm{g}\right)$. When incorporated into cigarette filters, the tharcoal is intended to remove diverse compounds from the vapour phase of smoke, including hydrogen cyanide, atnmonia, formaldehyde, acrolein, nitrogen dioxide, and other toxic agents. ${ }^{1-15}$ These have been shown to induce irritation or other biological changes in animals, tissue cultures, and organisms such as paramecia." ${ }^{1-i 5}$ For example, Thayer and Kensler found that charcoal filters reduced the cytotoxic activity of cigarette smoke on cultured human $\mathrm{KB}$ cells significantly, ${ }^{16}$ and Kensier and Battista found that charcoal filters reduced the clliary depressant activity of smoke. ${ }^{17}$ The effectiveness of charcoal and other adsorbent containing filters may be compromised by agents used in the manufacturing process (for example, water, plasticising agents, adhesives, and volatile flavouring material) ${ }^{12}$ In addition, charcoal and other filter adsorbants increase draw resistance-as the cigarette is smoked, the resistance increases. ${ }^{12}$

Another widely recognised drawback includes charcoal associated off-taste of the mainstream smoke. ${ }^{12}$ Problems are also encountered in processing charcoal during high speed cigarette manufacturing, including carbon fallout in pneumatic feed systems and tipping units."

Filter cavities partially filled with charcoal are also be prone to collapse. "This void in the filter may also be responsible in part for the plug wrap gaps that we have seen (see below). 
Charcoal cigarette filters therefore affect the composition and taste of cigarette smoke, but any advantages realised may be offset by shortcornings of consumer acceptance, fabrication problems, and manufacturing costs.

Cigarettes having charcoal filters occupy only a small niche in the US market $(<1 \%$; estimated by authorities at the US Department of Agriculture). ${ }^{18}$ Paradoxically, in other countries, such as Japan and Korea, very few cigarettes are sold without charcoal filters. ${ }^{18}$ Moreover, in countries where there is a great demand for lower tar products, the use of charcoal filters is increasing. ${ }^{11819}$

In previous studies, we evaluated the release of cellulose acetate filter fibres from the filters of popular brands of cigarettes. "While inspecting the cut surface of the filter for loose or cut cellulose acetate fibres, we noted charcoal granules on the filter surface of Lark cigarettes. This prompted us to conduct the current study, which shows that more than three quarters of the non-smoked Lark cigarettes had charcoal granules on the filter surface. All of our observations were made for packs of cigarettes opened in the laboratory and, in many instances, the cigarettes analysed had not been removed from the pack.

Marked differences were noted for the number of granules present on cigarettes from different packs. The pack to pack variations may be attributed in part to manufacturing and transportation of the cigarettes. It would also be reasonable to predict that the number of charcoal granules would increase on the cut filter surface of cigarettes if the pack had been dropped, crushed, or manipulated repetitively, as would occur when transported by an individual daily.

The stereo zoom microscope proved effective for documenting charcoal particles on the filter, including charcoal that was on the filter surface and enmeshed within the filter bloom which consisted of thousands of individual cellulose acetate fibres. However, precise counting of the charcoal granules on a large number of cigarettes was arduous. For two experienced readers, the charcoal enumeration scores were consistent $(0.42, \mathrm{~K}$ test, $A v B$ ). In contrast, scores recorded for a third, and less experienced reader, were marginally consistent with those of the other two readers $(0.25, \mathrm{C} v \mathrm{~A}$; and $0.28, \mathrm{C} v \mathrm{~B})$. To ensure an accurate and objective evaluation, we recommend that future studies seeking quantification of charcoal particles explore alternative methods. For example, one could isolate the charcoal granules by cutting off the filter end and dissolving this segment in an organic solvent. Thereafter, a conventional electronic particle counter could be used to obtain size and number distribution profiles of the charcoal particles.

Having established that charcoal granules are situated precariously on the filter surface of the majority of non-smoked cigarettes, we tried to discover whether the carbon was released during human smoking. With a modified cigarette device, we have shown that charcoal granules of variable size and number were released from all cigarettes that had been smoked by consenting adults. The entrapment device contributed relatively little resistance to draw. Moreover, when queried, none of the smokers noted any change in draw because of the cigarette holder.

It was noteworthy that the cavity of the Lark cigarette filter was less than half filled with charcoal. We also observed appreciable variation from cigarette to cigarette in the amount of charcoal in the filter cavity. As discussed elsewhere, if the cigarette filter chamber is not filled completely with charcoal, the smoke is not exposed to the charcoal as designed and therefore is not filtered. ${ }^{12}$ For cigarette filter cavities that are incompletely filled, the smoke follows a path of least resistance and, during smoking, bypasses the carbon particles located on the bottom of the cigarette filter chamber. ${ }^{12}$

To further define a more accurate assay for measuring the fallout of filter fibres and charcoal during smoking behaviour, we have developed an additional assay. In this procedure (Pauly $\mathrm{JL}$, et al., studies in progress), the volunteers smoked a cigarette in the usual manner and afterwards rinsed their mouth with water. The mouth washing was collected and passaged over a filter. The filter was then examined microscopically and the number of cigarette filter derived elements was identified and enumerated. The results of these ongoing studies confirm and extend the observations reported here on the discharge of charcoal granules during smoking.

As described by Shepherd, ${ }^{11}$ the triple granular filter possesses "an inherent defect, which though known about for a number of years..." The defect is the collapse of the central cavity containing the charcoal granules. "This is due in part to the bending of the central, charcoal filled compartment during transport of the filter to the hopper feed of the cigarette making machine. As the cavit is only partially filled with charcoal granules and therefore structurally weak, it can collapst as the filter travels through the curves in the pneumatic filter transport system. ${ }^{\text {" }}$

The defect of the triple granular filte becomes significant during the high speed used in filter transport systems. ${ }^{11}$ It is likel that this defect may also be attributed is part to high speed cigarette making machint $(>10000$ cigarettes per minute) and cigaretti packaging machines ( $>250$ boxes minute).

Our studies have shown that the charcos granules can be discharged from the interio charcoal compartment to the surface of the ter through the gaps. These gaps, which we observed in $70.4 \%$ of the unsmoked cigaretter observed in $70.4 \%$ of the unsmoked cigare wre formed by the separation the heat gen wrapping papers. Additionally, the heat ges ated during smoking may affect the adhest so as to loosen the wrapping paper and there create channels through which the charc granules may reach the filter surface and inhaled or ingested.

We have learned recently of Philip Mos documents that showed that this tobacco $\mathrm{cos}^{\circ}$ 
pany was aware of "carbon fallout" in the 1960 s and "filter fiber fallout" in the 1970 s. For example, Philip Morris had established a protocol to define the number and size range of carbon and microporous filter material fallout. ${ }^{20}$ it In this protocol, cigarettes were given "unit puffs" and particles released were captured onto either black (for "microporous material") or white (for "carbon") Millpore pads (Millipore Corporation, Bedford, Massachusetts). Thereafter, the pads were examined microscopically and the number of particles of different sizes was determined. In one study, ${ }^{20}$ the size range and number of particles observed in one experiment in which "10 cigarettes were given five unit puffs" were as follows: $5 \mu \mathrm{m}$ ( $\mathrm{n}=20$ particles); $6-10 \mathrm{~mm}(38)$; $11-20 \mu \mathrm{m}(22) ; 21-30 \mu \mathrm{m}(14) ; 31-40 \mu \mathrm{m}$ (10); $41-50 \mu \mathrm{m}(6) ; 51-70 \mu \mathrm{m}(9) ; 71-80 \mu \mathrm{m}$ (2); $81-100 \mu \mathrm{m}(1) ; 200 \mu \mathrm{mm}(1)$; and $300 \mu \mathrm{m}$ (1). Thus there was a wide (150-fold) range in carbon size. It was significant that that they observed many microparticles ( $\leqslant 10 \mu \mathrm{m}$ ) in the fallout assays that would be classified by the National Institute on Occupational Safety and Health (NIOSH) as "respirable" and which, by the NIOSH definition of "respirable", could penetrate deep into the lung, including the area of the alveoli. ${ }^{23}$ The larger carbon particles (for example, $-300 \mu \mathrm{m}$ ) released by the cigarettes would be visible readily to the naked eye. Lark cigarettes are marketed by Philip Morris as part of their international package, and the filters of these cigarettes will be analysed.

A study published in 1958, supported by the Brown and Williamson Tobacco Corporation, documented the release of charcoal. ${ }^{23}$ Cellulose acetate filter fibres and other filter elements were discharged from the filters of all six cigarette brands tested. ${ }^{23}$ These investigators noted that: "sharp, angular fragments and aggregates of charcoal were common in every sample of Tareyton smoke deposits examined." Further, they concluded that: "In view of the accumulated medical evidence concerning the greater irritation to the respiratory tract from a solid particle [charcoal] with a coating of hydrocarbon [tar] than from either the particle or hydrocarbon alone, the need to eliminate soltd particulate material from the smoke stream would be indicated.",23.

It is widely recognised that certain types of inhaled particles may promote the development of various lung diseases. Specifically, ample evidence has been obtained using differ ent laboratory animal models to show that many different types of particles may lead to progressive lung injury which includes inflammation, fibrosis, alveolar epithelial hyperplasia, metapiasia, and neoplasia. ${ }^{24}$ To cite but a single example, 17 different solid particles carcinogenic in rats exposed by infralation or instillation have been identified. ${ }^{24}$

Particle induced and fibre induced lung tissue damage are thought to be similar, and the underlying mechanisms have been reviewed recently. ${ }^{23} 34$ Reports of carcinogenesis from these materials also describe concurrent chronic inflammation, epithelial prolifera- tion, and fibrosis. ${ }^{24}$ Included in this listing of solid particles are activated carbon, carbon black, coal dust, and diesel soot. ${ }^{24}$ Whether rodent models of inhalation toxicology are adequate surrogates for predicting human cancer risk has been debated, and is currently under investigation. ${ }^{24}$

Different conception models have been prem sented recently on the ways in which particles ${ }^{24}$ and fibres ${ }^{29}$ might lead to tissue injury. These include mechanisms whereby particles or thbres are recognised as foreign bodies and stimulate phagocytic leucocytes (for example, macrophages and neutrophils) or lung epithelial cells (type I or II) to produce cytokines that augment the growth of mutated cells. Phagocytic leucocytes are known to secrete oxidants (for example, superoxide, hydrogen peroxide, and hydroxyl radicals) that may damage DNA and promote cell mutations. The inhaled particles or fibres, which resist degradation in the lung, may also serve as a matrix which is coated with carcinogens or promutagens that are released at variable rates over a prolonged period. These chemical agents may form DNA adducts which lead to tumour formation. In addition, particles and fibres within the cell may cause physical harm during cell division, leading to chromosomal aberrations (e.g. aneuploidy).

These findings raise serious questions about the health risks involved with the inhalation or ingestion of charcoal granules by the millions of people worldwide, and particularly in East Asia, who have expressed a preference for charcoal filter cigarettes.

We have observed that during human smoking, charcoal granules are released from charcoal filter cigarettes into the mouth. From the mouth, they are likely to be inhaled or ingested. The portion of particles distributed to the respiratory tract is not known. Some charcoal particles would be inhaled with cigarette smoke. Smaller carbon particles could penetrate deep into the lung, and those that are $10 \mu \mathrm{m}$ or less in size could be deposited in the alveolar area.

Larger charcoal particles may impinge on the walls of the upper respiratory tract. The clearance of the particles from different lung sites may be impeded by smoke associated damage to ciliated epithelial cells that mediate mucociliary escalator clearance mechanisms.

There is no known mechanism whereby the charcoal would be degraded in vivo. The charcoal particles containing gas phase toxins adsorbed from cigarette smoke may be phagocytosed by lung macrophages. We have observed large carbon particles in living macrophages isolated from fresh human lung tissue excised from patients with lung cancer. ${ }^{26}$

Charcoal particles, like other foreign bodies including inhaled fibres, are likely to activate macrophages to secrete agents that may damage adjacent cells. A partial listing of these macrophage derived factors includes $c y-$ tokines, enzymes, nitric oxide, and oxygen intermediates; tissue iniury that may be induced by these agents has been reviewed elsewhere. ${ }^{25} 2738$ 
It is also likely that some carbon particles released from the cigarette filter during smoking would be trapped by saliva or mucus and swallowed. The charcoal would serve as a carrier of gas phase toxins delivered to more than 20 feet of the gastrointestinal tract.

\section{Conclusions}

Many smokers perceive the cigarette filter as a safety device. However, the safety of the filter has not been investigated critically. This study indicates that charcoal granules are released from the charcoal filter of Lark cigarettes when smoked by healthy adult smokers. This finding extends our previous observations indicating a defect in the filters of cigarettes. ${ }^{*}$ Further research should be directed toward determining whether the released cigarette filter components increase the smoker's risk of chronic inflammation and malignant transformation.

In the United States today, tobacco products are subject to little regulation. ${ }^{29}{ }^{30}$ Meanwhile, the unsuspecting smoking public is being unknowingly and unwittingly battered by components of cigarette filters, subjecting them to bioresistant elements that may augment smoking related health risks. The smoker should be an educated consumer. Consequently, we believe the results presented herein have serious implications for future cigarette filter design and serve to illustrate the need for tobacco product regulation.

\section{Addendum}

After submitting this paper for publication, we learned of two recent reports that relate to our studies. ${ }^{31}{ }^{32}$ One report notes that: "Solid filters have nowadays a slight advantage against cavity filters, since in high-speed cigarette manufacture the filters are pneumatically supplied to the machine. This means that the cavity becomes the 'weak point' of the filter during the manufacturing and transfer process." The other report is a US patent that describes the invention of an optical sensor for detecting a defect in dual and triple granular charcoal filters. ${ }^{30}$ For cigarettes with non-defective filters, "no charcoal particle enters the mouth of a smoker when he or she smokes." The inventors claim that: "The filter end face of the dual-filter-type filter must be inspected in its manufacturing process." As a result of the inspection: " $A$ defective filter cigarette to whose filter end face charcoal particles are exposed, or through which charcoal particles are seen must be removed from the manufacturing line." Further: "A filter cigarette with a defective filter end face must be excluded because it is a defective product." (Emphasis added.)

This work was supported in part by grant CA-67827 from the National Institutes of Health. This paper was presented at the 88th Annual Meeting of the American Association for Cancer Research, 12-16 April 1996, San Diego, California, USA.

1 Hoffmann D, Djordjevic MV, Brunnemann $\mathrm{KD}$. Changes in cigarette design and composition over time and how they influence the yield of smoke constituents. $f$ Smoking Rel Dis 1995;6:9-23.

2 Wynder EL, Hoffmann D. Smoking and lung cancer: scientific challenges and opportunities. Cancer Res 1994; 54 tific challen.

3 Browne CL. The design of cigarettes, 3rd ed. Charlotte, North Carolina: Filter Products Division, Hoechst Celanese Corporation, 1990: 1-119

4 Pauly $\mathrm{JL}$, Allaart HA, Rodriguez $\mathrm{MI}$, Streck RJ. Fibers released from cigarente filters: an additional health risk to the smoker? Cancer Res 1995; 55: 253-8.

5 Gori GB, Bock FG, eds. Banbury report No 3. A safe cigarette? Cold Spring Harbor: Cold Spring Harbor Laboratory Press, 1980.

6 Kozlowski LT, Pope MA, Lux JE. Prevalence of the misuse of ultra low-tar cigarettes by blocking filter vents. Am $\mathrm{F}$ Public Health 1988;78:694-5.

7 Benowitz NL. Health and public policy implications of "low yield" cigarettes. N Engl f Med 1989;320:1619-21.

8 US Patent $3,251,365$. Keith $\mathrm{CH}$, Norman V, Bates WW Tobacco smoke filter. May 17, 1966.

9 Kluger R. Ashes to ashes: America's hundred-year cigarette war, the public health, and the unabashed triumph of Philip Morris. New York: Alfred A Knopf, 1996.

10 Fleiss $]$. Statistical method's for rates and proportions. New York: Wiley, 1981.

11 Shepherd RJK. New charcoal filters: new innovations in charcoal filters meet the challenges of high-speed cigarette making. Tobacco Reporter 1994; February: 40-6.

12 Raker $R$, Jadot P, Jaccard P. Carbon action: Baumgartner introduces charcoal filter designs using less carbon. Tobacco Reporter 1996; September: 38-42.

13 US Department of Health and Human Services. The healh consequences of smoking: the changing cigarente. A report of the Surgeon General, 1981. Rockville, Maryland: Public Health Service, Office on Smoking and Health, 1981. (DHHS Publication No (PHS) 81-50156.

14 Tiggelbeck D. Vapor phase modification-an under-utilized technology. In: Wynder EL, Hoffmann D, Gori GB, eds. Smoking and health 1975. Proceedings of the third world con. ference on smoking and health, New York, 2-5 fune 1975.

15 Anonymous. Cigarette filters-what they can do. Tobacco Reporter 1967; February: 23-32.

16 Thayer PS, Kensler CJ. Cigarette smoke: charcoal filter reduce components that inhibit growth of cultured human cells. Science 1964;146:642-4.

17 Kensler CJ, Battista SP. Components of cigarette smok with ciliary-depressant activity: their selective removal by with ciliary-depressant activity: their selective removal by filters containing activate

18 Bickers CE. US filter factory expands to meet growing demand. World Tobacco 1995; November:48.

19 Glass C. Carbon, please: PICA makes the carbon for cigarette filters. Tobacto Reporter 1996;June:66-8.

20 Johnson VC. Fallout of cigarette filter material. Philip Morri Inc, Jan 7, 1970.

21 Johnson VC. Particle fall out. Philip Morris Inc, Apr 14, 1970.

22 Oberdörster $G$, Ferin J, Lehnert BE. Correlation betwee particle size, in vivo particle persistence, and lung injur In: Biopersistence of respirable synthetic fibers and mine als. Environ Health Perspect 1994; 102(suppl 5):173-80

23 Farr WK, Revere A. Examination of whole cigarette smoke bj light and electron microscopy. New York: The Life Extensio Foundation, 1958

24 Mauderly JL. Lung overload: the dilemma and opportuni ties for resolution. Inhalation Toxicol 1996;8(suppl):1-28.

25 McClellan RO, Hesterberg TW. Role of biopersistence the pathogenicity of man-made fibers and methods for evaluating biopersistence: a summary of two round-tabl. discussions. In: Biopersistence of respirable synthetic fibers and minerals. Environ Health Perspect 1994;10? (suppl 5):277-83.

26 Streck RI, Jezewski HM, Rodriguez M五, Kunley EL, Ríc GA, Braun KM, Pauly JL. A method for isolating humat lung macrophages and observations of fluorescent phag Immunol Methods 1994; 174:67-82.

27 Barretr JC, Lamb PW, Wiseman RW. Multiple mechanisss for the carcinogenic effects of asbestos and other miner fibers. Environ Health Perspect 1989;81:81 -9 ,

28 Harris CC, Lechner JF, Brinkley BR, eds. Cellular of molecular aspects of fiber carcinogenesis. Current commutich tions in cell and molecular biology. Cold Spring Harbor: $C$ Spring Harbor Laboratory Press, 1991:1-211.

29 Slade J, Connolly GN, Davis RM, et al. Report of to tobacco research study group in tobacco products. Tob Control 1992;1 (suppl):54-9.

30 Lynch BS, Bonnie RI eds. Growing up tobacco free Washing DC: National A

ton, DC. National Academy Press, $1994: 233-53$. grin momentum. Tobacco f Int 1996,June:46 -8.

32 US Patent 5,583,633. Matsumura T, Muramoto H, Kond $M$. Device for detecting a defect in charcoal type filt manufactured filter cigarettes. 10 December, 1996. 